\section{(6) OPEN ACCESS} Aspetar, Qatar Orthopaedic and Sports Medicine Hospital, Doha, Qatar

${ }^{2}$ Performance Department, British Athletics, Birmingham, UK

${ }^{3}$ International Association of Athletics Federations (IAAF) Medical and Anti-doping Commission, Montecarlo, Monaco

Correspondence to Dr H Paul Dijkstra, Sports Medicine Department, Aspetar, Qatar Orthopaedic and Sports Medicine Hospital, PO Box 29222, Doha, Qatar; paul.dijkstra@aspetar.com

Received 24 October 2013 Revised 18 January 2014 Accepted 6 February 2014

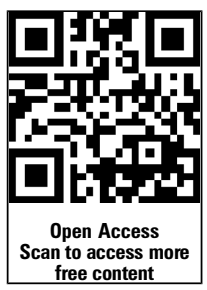

\title{
Managing the health of the elite athlete: a new integrated performance health management and coaching model
}

\author{
H Paul Dijkstra, ${ }^{1}$ N Pollock, ${ }^{2}$ R Chakraverty, ${ }^{2}$ J M Alonso ${ }^{1,3}$
}

\section{ABSTRACT}

Elite athletes endeavour to train and compete even when ill or injured. Their motivation may be intrinsic or due to coach and team pressures. The sports medicine physician plays an important role to risk-manage the health of the competing athlete in partnership with the coach and other members of the support team. The sports medicine physician needs to strike the right ethical and operational balance between health management and optimising performance. It is necessary to revisit the popular delivery model of sports medicine and science services to elite athletes based on the current reductionist multispecialist system lacking in practice an integrated approach and effective communication. Athlete and coach in isolation or with a member of the multidisciplinary support team, often not qualified or experienced to do so, decide on the utilisation of services and how to apply the recommendations. We propose a new Integrated Performance Health Management and Coaching model based on the UK Athletics experience in preparation for the London Olympic and Paralympic Games. The Medical and Coaching Teams are managed by qualified and experienced individuals operating in synergy towards a common performance goal, accountable to a Performance Director and ultimately to the Board of Directors. We describe the systems, processes and implementation strategies to assist the athlete, coach and support teams to continuously monitor and manage athlete health and performance. These systems facilitate a balanced approach to training and competing decisions, especially while the athlete is ill or injured. They take into account the best medical advice and athlete preference. This Integrated Performance Health Management and Coaching model underpinned the Track and Field Gold Medal performances at the London Olympic and Paralympic Games.

\section{INTRODUCTION}

While the health benefits of moderate exercise have been well documented, exercise training and competition at elite level may significantly increase the health risk to the athlete. Numerous research articles focusing on athlete injury and illness surveillance as well as injury and illness prevention have been published in the past 10 years. With regard to injury and illness in Track and Field athletes, data have predominantly been surveillance studies from major competitions with the limitation of only documenting injury and illness during the competition phase while the potentially significant influence of chronic injury and illness was not typically noted. ${ }^{1-3}$ Of the 2079 Track and Field athletes competing at the 2012 Olympic Games, $17.7 \%$ sustained injuries and $10.5 \%$ reported illnesses during the Olympics. ${ }^{3}$ A prospective cohort study on elite Swedish athletes highlighted the prevalence of overuse injuries and the importance of injury surveillance on a routine basis. ${ }^{4}$

Our own unpublished data highlight that the vast majority $(80 \%)$ of the British Track and Field athletes selected to compete at the London 2012 Olympic Games had injuries or illnesses requiring management before, during and after the Games. Of these athletes, nearly $25 \%$ had undergone surgery during their athletic career and a further $15 \%$ had surgical interventions after the Games. These facts highlight the importance of establishing appropriate services to manage athlete health on a continuous basis and not only during major competitions.

Sports medicine for elite athletes is challenging on many fronts and return-to-play (RTP) decisionmaking is complex. ${ }^{5}$ Creighton $e t a l^{6}$ proposed a 3-step decision-based model for RTP with the aim of clarifying the process that clinicians use consciously and subconsciously when making RTP decisions. A critical element in the environment for successful decision-making is integration and communication between disciplines, to facilitate optimal training and competition while also managing the athlete's long-term health-often two contradictory elements in the elite athlete. It is well recognised that organisational structure can affect the performance of teams. The optimisation of the structure of medical and coaching teams managing the elite athlete should therefore be a strategic priority for all clubs and sporting organisations.

The purpose of this paper was to describe a pragmatic model for the structuring of medical and science support services to elite athletes. We outline the contributions in a management model of the Sport and Exercise Medicine (SEM) specialist, as they seek to strike the right ethical and operational balance between health management and optimising athletic performance. We discuss aspects of the model and health strategy used by UK Athletics (UKA) before the 2012 Olympic Games.

\section{THE CHANGING ROLE OF DOCTORS: FROM GENERAL PRACTITIONERS WITH AN 'INTEREST' IN SPORT TO SPECIALIST SPORTS MEDICINE PHYSICIANS}

Historically, medical provision for athletes consisted of reactive, injury centred service, delivered by general practitioners, orthopaedic surgeons and other clinicians with an interest in sport. ${ }^{7}$ This 
reactive injury-centred approach often neglected the contribution to health and performance of chronic injuries and medical conditions such as low-grade infections, vitamin D deficiency, asthma and allergy. ${ }^{8} 9$

In many countries, medical practitioners may perform up to 6 years of further training to become specialist sports medicine (or SEM) physicians. ${ }^{10}$ Based on their specific expertise and breadth of responsibility, specialist sports medicine physicians may be considered best positioned to provide clinical leadership to the integrated multidisciplinary teams supporting the health and performance goals of elite athletes. Their primary responsibility is the comprehensive health management of the athlete. ${ }^{11}$

Clubs and organisations responsible for the health management of individual athletes and teams face a number of health-related challenges, and an increasing number are employing team doctors on a full-time or sessional basis. However, this employment has the potential to influence clinical decisionmaking in favour of organisational performance goals rather than longer term individual health objectives. These and other challenges may be addressed within an integrated performance health and coaching structure where roles and responsibilities are transparent and there is a clear system of clinical governance and external professional appraisal. We list some of the existing health challenges faced by physicians with possible solutions in table 1 .

\section{INTEGRATED PERFORMANCE HEALTH MANAGEMENT AND COACHING OF THE ELITE ATHLETE}

The current SEM model improved on the traditional medical model where the physician (usually a general practitioner interested in sport) was the 'primary contact'. ${ }^{12}$ The improved model recognises the multidisciplinary nature of the athlete's 'primary professional contact' who may be a physiotherapist, sports physician, team doctor, general practitioner, orthopaedic surgeon, soft tissue therapist, podiatrist, osteopath, chiropractor, nutritionist, physiologist, biomechanist or psychologist.

Although essentially true, this improved model still emphasises the reductionist approach with each discipline potentially operating in its own specialist silo with little focus on holistic athlete health management, effective communication, integration and understanding to facilitate decision-making. There is no 'case-manager', and it is then left to the often ill-equipped athlete and coach to manage health and performance contributions from a number of clinical and scientific specialists. This disjointed multispecialist (reductionist) approach has the potential to negatively influence health and performance when the athlete is injured or ill.

This approach might promote the search for objective measures and precision in the 'evidence based' application of SEM and science. It however ignores the reality that optimal athlete health is a spectrum ranging from complete wellness (but with possible intrinsic and extrinsic risk factors already changing this) to multiple existing injuries and illnesses-especially in the older athlete. Is it then, taking into account the complex environment of elite performance, the 'duty' of the team physician to protect the bealth and welfare of the athlete? ${ }^{13}$ Or is the primary role to sensibly inform and involve the athlete, providing a safe framework to make the best performance decisions, sometimes even compromising athlete 'health and welfare'?

Clever decision-making about training and competing is essential and sporting bodies should embrace a new developing culture where performance coaching is integrated into a holistic approach to comprehensive health management and decisionmaking. The secret of a successful performance outcome is to take a broad view of the athlete's health, not only pathology driven but also at a functional level. This holistic approach includes strategies to reduce the risk of injury and illness as well as the management of existing health issues. Medical teams

Table 1 Current challenges for sports physicians and suggested solutions

Challenge
Doctors lacking specialist training employed to manage the health of elite athletes
Doctors practising in isolation; decisions made without broader team consultation
Physiotherapists managing the total health of elite athletes
Doctors are employed by clubs; this fact might influence their objective clinical
decision-making

Doctors are clinically line managed by non-medical team members or non-clinicians. This fact potentially challenges athlete medical confidentiality, access to medical records and ultimate clinical responsibility

Managers or coaches refer athletes to specialist medical services without involving the medical team/responsible doctor

The Head Coach influences/over rules clinical decisions by the medical team or doctor

\section{Solution}

Employ only well-qualified specialist sports medicine physicians to manage the total health of athletes

Doctor should practise and make decisions as part of a comprehensive coaching and medical support team

Physiotherapists are qualified to manage musculoskeletal health but not the total health of athletes

Clear role definition with internal and external clinical governance (eg, appraisal and revalidation process by the appropriate external bodies such as the Faculty of Sport and Exercise Medicine and General Medical Council in the UK)

Employ appropriately qualified sports medicine physicians with contractual arrangements detailing their ultimate clinical responsibility Culture and contracts within sporting organisations should consider the issue of medical confidentiality

The medical department is responsible for all the clinical medical aspects including referring athletes for specialist investigations or treatments. Athletes have the right to more than one medical opinion; it is important to develop and agree on a clear referral protocol/policy

Within a performance environment, the clinical advice may not always be heeded. The Performance Director to whom the medical team is accountable may, in conjunction with the athlete and in receipt of the medical opinion, choose an alternative path. The procedure and documentation around this process should be clear. It is, however, unacceptable for a non-clinician (coach) to make/over rule medical decisions where the athlete lacks the capacity to make a clear decision (eg RTP in concussion) 


\section{Performance Coaching}

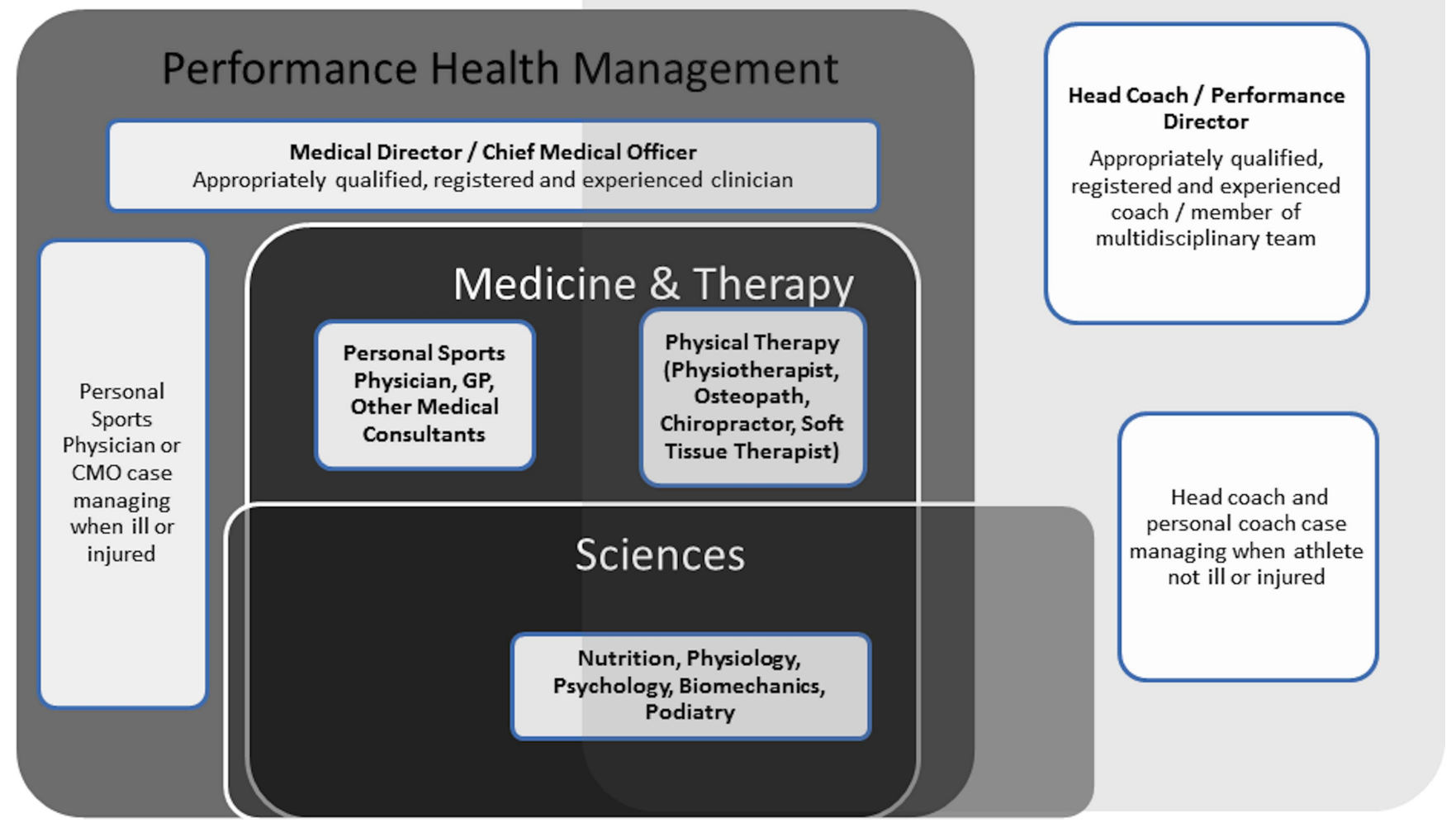

Figure 1 The Integrated Performance Health Management and Coaching Model. All the specialties operate in the performance health and coaching 'box'. Health (injury, illness and prevention) is managed by specialist sports medicine physicians (led by the CMO/Medical Director); coaching is managed by the Head Coach. Both departments are managed by the Performance Director or (CEO) depending on the structure and size/culture of the organisation/club. The health and coaching departments operate in synergy and also 'independently' with appropriate autonomy at times. All professional service providers are independently registered and professionally governed by the relevant Professional Bodies like the General Medical Council and the Faculty of Sport and Exercise Medicine for physicians in the UK. CEO, Chief Executive Officer; CMO, Chief Medical Officer; GP, general practitioner.

should also be prepared to prioritise the utilisation of sports medicine and science to optimise and improve performance especially for elite athletes with established health problems or disabilities (figure 1).

The proposed Integrated Performance Health Management and Coaching model focuses on the operational integration of the two key departments: health and coaching to improve performance. The two departments should ideally be line managed as autonomous units operating in complete synergy towards a common performance goal. It is important to refine the specific roles and responsibilities of the role players within each department. Coaches, for instance, should have a working knowledge of important injuries and illnesses, and doctors should have a thorough understanding of the physiological and mechanical demands of the specific sport or event.

The Chief Medical Officer (CMO) or Medical Director leads the health department (injury, illness and health risk reduction) and is a medical doctor with specialist sports medicine training and experience. The ultimate clinical and medicolegal responsibility is with this individual. Within the health department, specialist sports medicine physicians with a thorough knowledge of the specific sport are experts with respect to the current best practice medical options and implications. They are the case managers of all athletes with existing or chronic injury or illness and operate best when supported by a team of sport-specific medical and science specialists with the ability to analyse the functional or biomechanical background to injuries.

The Head Coach leads the coaching department. This senior individual has coaching and performance expertise and line manage all the coaches, including the strength and conditioning coaches. Coaches and athletes are experts on the athlete's values and sport-specific performance preferences as well as training practices to achieve a specific goal.

The Performance Director or Chief Executive Officer, depending on the size of the organisation, manages the two departments and implements the performance strategy and vision of the board of directors. They should be formally accountable to the board in a transparent way.

It is important to consider how the specialists integrate their individual expertise to best serve the athlete. Evidence-based sports medicine practice has become more and more important over the past 20 years, especially with the establishment of specialist training programmes in different parts of the world. Progress has also been made in the athlete-centred care and decision-making, but much more work is needed to better understand and narrow the 'preference-evidence-practice' gap in SEM. Quill and Holloway ${ }^{14}$ have developed a five-step framework for reconciling the tension between 'evidence-based' and 'preference-based' medicine, which they believe can help in leveraging the best of both approaches (table 2). 
Table 2 Balancing approaches to achieve goal-oriented patient care

\begin{tabular}{lll}
\hline Step & $\begin{array}{l}\text { Evidence-based } \\
\text { medicine }\end{array}$ & Preference-based medicine \\
\hline 1 & $\begin{array}{l}\text { Asking focused } \\
\text { questions }\end{array}$ & Proper set-up and introduction \\
2 & Finding the evidence & $\begin{array}{l}\text { Eliciting values and preferences and learning } \\
\text { about goals } \\
\text { Debiasing strategies and responding to } \\
\text { emotions }\end{array}$ \\
4 & $\begin{array}{l}\text { Performing critical } \\
\text { appraisal }\end{array}$ & $\begin{array}{l}\text { Making a recommendation and seeking } \\
\text { consensus } \\
\text { Assuring non-abandonment and follow-up }\end{array}$ \\
\hline
\end{tabular}

Preference-based medicine relies on views from patients and families (athletes, coaches) about their specific goals of care as well as treatment preferences in light of a realistic assessment of risks and benefits. That assessment requires sports medicine clinicians to systematically find and appraise the available medical evidence and synthesise and communicate it effectively to athletes and coaches. Clinicians must then gather critical evidence about values and preferences from athletes and coaches. Finally, clinicians, athletes and coaches must integrate both types of information to reach the optimal decision. ${ }^{14}$ There will obviously be a different preference and attitude towards risk-taking for a local club event as opposed to the Olympic Games, for instance.

\section{THE UKA (NOW BRITISH ATHLETICS) EXPERIENCE}

UKA has adapted the provision of medical and science services to Olympic and Paralympic Track and Field athletes based on some of the core principles of integrated performance health management and coaching. All the funded Olympic and Paralympic athletes have comprehensive private medical insurance. This is an important strategy as a large number of athletes (including some of the medallists) competed at the London Olympic Games with one or more significant pathologies needing continuous medical management over a long period. Readiness to compete decisions were based on an integrated process of discussion involving the athlete, coach, doctor and physiotherapist.

\section{Structure and governance of the medical team}

In preparation for the London 2012 Olympic and Paralympic Games, the comprehensive health management component was governed by the first author of this paper, employed at the time by UKA as the CMO who line managed the other employed UKA Sports Medicine Physicians. The UKA Medical Commission, chaired by the CMO, advised on clinical medical policy, processes and governance. This commission, with the London and Midlands Medical Officers, the Chief Physiotherapist, a science representative, the UKA Head coaches or their representatives and the National Lead for Medicine and Science as members, met 3-5 times per year. The UKA National Lead for Medicine and Science, a senior and experienced sport-specific physiotherapist line, managed the CMO as well as the Chief Physiotherapist and individual sport science practitioners. The National Lead for Medicine and Science reported directly to the UKA CEO as did the individual Head Coaches. The key role players worked in very close relationship with the two Head Coaches, responsible for the performance coaching aspects of the Olympic and Paralympic teams respectively, in an

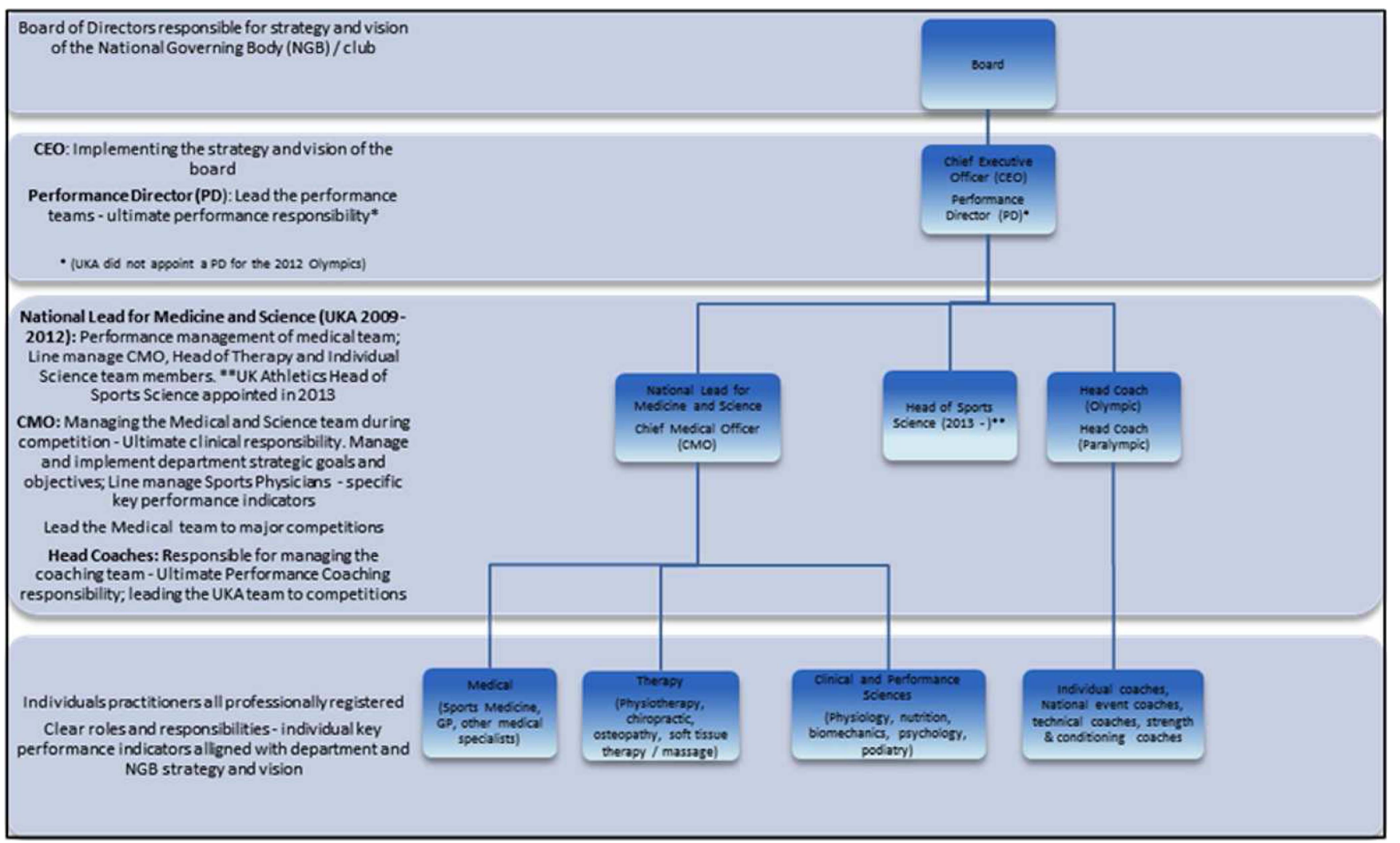

Figure 2 A model for structuring medical and science services and function-based on aspects of the current and previous (2009-2012) UK Athletics Performance Department model. CEO, Chief Executive Officer; GP, general practitioner. 
Table 3 The five-colour health and performance risk grading system

\begin{tabular}{|c|c|c|}
\hline $\begin{array}{l}\text { Health status: state-specific conditions } \\
\text { where applicable }\end{array}$ & Medical/injury (health) risk & Performance risk* \\
\hline Healthy—no illness/injury & $\begin{array}{l}\text { Minimal risk to your future health based on your current } \\
\text { health status } \\
\text { It should be noted that this grading is fluent and might } \\
\text { change at any time should you become ill or injured. It is your } \\
\text { responsibility to consult with a Sports Physician or } \\
\text { Physiotherapist immediately if you have any health concerns }\end{array}$ & $\begin{array}{l}\text { Minimal risk of suboptimal performance based on your } \\
\text { current health status and the nature of the sport/event } \\
\text { It should be noted that this grading is fluent and might } \\
\text { change at any time should you become ill or injured. It is } \\
\text { your responsibility to consult your coach/manager } \\
\text { immediately if you have any concerns }\end{array}$ \\
\hline $\begin{array}{l}\text { Asymptomatic chronic illness/injury (well } \\
\text { controlled)—for example } \\
\text { - Asthma_-well controlled; } \\
\text { Insufficient Vitamin D; } \\
\text { - Previous ACL injury }\end{array}$ & $\begin{array}{l}\text { Low risk to your health due to the nature of the conditions } \\
\text { stated in column one } \\
\text { It should be noted that this grading is fluent and might } \\
\text { change at any time should the condition(s) become } \\
\text { symptomatic. It is your responsibility to consult with a Sports } \\
\text { Physician or Physiotherapist immediately if you have any } \\
\text { health concerns }\end{array}$ & $\begin{array}{l}\text { Low risk of suboptimal performance due to the nature of the } \\
\text { conditions stated in column one and the demands of the } \\
\text { sport } \\
\text { It should be noted that this grading is fluent and might } \\
\text { change at any time should the condition(s) become } \\
\text { symptomatic. It is your responsibility to consult your coach/ } \\
\text { manager immediately if you have any concerns }\end{array}$ \\
\hline $\begin{array}{l}\text { Symptomatic illness/injury in full training/ } \\
\text { competition - for example } \\
\text { Previous ACL/partial meniscectomy with } \\
\text { mild effusion/pain associated with } \\
\text { loading/training }\end{array}$ & $\begin{array}{l}\text { Mild risk to your health due to the nature of the conditions } \\
\text { stated in column one } \\
\text { It should be noted that this grading is fluent and might } \\
\text { change at any time should the condition(s) become } \\
\text { symptomatic. It is your responsibility to consult with a Sports } \\
\text { Physician or Physiotherapist immediately if you have any } \\
\text { health concerns }\end{array}$ & $\begin{array}{l}\text { Mild risk of suboptimal performance due to the nature of } \\
\text { the conditions stated in column one and the demands of the } \\
\text { sport } \\
\text { It should be noted that this grading is fluent and might } \\
\text { change at any time should the condition(s) become more } \\
\text { symptomatic. It is your responsibility to consult your coach/ } \\
\text { manager immediately if you have any concerns }\end{array}$ \\
\hline $\begin{array}{l}\text { Symptomatic illness/injury with modified } \\
\text { training — for example } \\
\text { Recent stress fracture, asymptomatic and } \\
\text { doing modified training but still unable } \\
\text { to sustain normal training load }\end{array}$ & $\begin{array}{l}\text { Moderate risk to your health due to the nature of the } \\
\text { conditions stated in column one } \\
\text { It should be noted that this grading is fluent and might } \\
\text { change at any time should the condition(s) become } \\
\text { symptomatic. It is your responsibility to consult with a Sports } \\
\text { Physician or Physiotherapist immediately if you have any } \\
\text { health concerns }\end{array}$ & $\begin{array}{l}\text { Moderate risk of suboptimal performance due to the nature } \\
\text { of the conditions stated in column one and the demands of } \\
\text { the sport } \\
\text { It should be noted that this grading is fluent and might } \\
\text { change at any time should the condition(s) become more } \\
\text { symptomatic. It is your responsibility to consult your coach/ } \\
\text { manager immediately if you have any concerns }\end{array}$ \\
\hline $\begin{array}{l}\text { Symptomatic illness/injury —-no training- } \\
\text { for example } \\
\text { Pneumonia with high fever } \\
\text { HOCM }\end{array}$ & $\begin{array}{l}\text { High risk to your health due to the nature of the conditions } \\
\text { stated in column one } \\
\text { The medical advice is that training and competition } \\
\text { should be avoided } \\
\text { It should be noted that this grading might be fluent and } \\
\text { might change at any time should the nature of the condition } \\
\text { (s) change. It is your sole responsibility if you decide not to } \\
\text { adhere to the medical advice and to consult with a Sports } \\
\text { Physician or Physiotherapist immediately if you have any } \\
\text { further concerns }\end{array}$ & $\begin{array}{l}\text { High risk of suboptimal performance due to the nature of } \\
\text { the conditions stated in column one and the demands of the } \\
\text { sport } \\
\text { It should be noted that this grading is fluent and might } \\
\text { change at any time should the condition(s) become less } \\
\text { symptomatic - consult your coach/manager immediately if } \\
\text { you have any concerns }\end{array}$ \\
\hline
\end{tabular}

*The performance risk column did not form part of the official EMR system but guided performance discussions (between the athlete, coach and medical team).

†lt is important to consider high risk (often asymptomatic) medical conditions here.

ACL, anterior cruciate ligament; EMR, electronic medical record; HOCM, hypertrophic obstructive cardiomyopathy.

environment where a healthy professional tension and mutual autonomy governed decision-making (figure 2).

The CMO with final clinical responsibility for athlete health led the medical team to major camps and competitions while the National Lead for Medicine and Science managed the integrated performance aspects of the medical and science team. The aim was to align the management of medical and science practitioners with the company's strategic objectives and goals. These objectives and goals dictated the individual key performance indicators (KPIs) and core competencies that were developed and implemented by the medical team in conjunction with the Human Resources Department of UKA.

The development of KPIs focused on quality clinical services (facilities, teams, integrated electronic record keeping and responsible pharmaceutical dispensing), performance support and health screening (focusing on vitamin D, cardiac and respiratory health), resource management and rationing of services (cost conscious approach to sustainable health management), key stakeholder engagement (optimal communication especially with athletes and coaches; English Institute of Sport; British Olympic Association; UKA CMO International Panel of Experts in SEM) and finally continued professional development of individual practitioners and the medical and science team.
After the London 2012 Olympic Games, UKA appointed a Performance Director and also a Head of Sports Science in addition to the CMO and Head Coaches-all line managed by the Performance Director.

\section{Infrastructure development}

Medical care for elite athletes is continually provided at two distinct levels: the medical or diagnostic environment, sometimes at a hospital or sports medicine institute with regular interaction with other health colleagues, and also the performance environment at the athlete training centres, interacting with athletes, coaches, therapists and scientists on the track and in the weights room.

UKA prioritised the development of appropriate clinical settings to deliver medical and therapy services. In addition to developing trackside medical facilities at the National Training Centers in London and Loughborough, UKA also invested in a national diagnostic centre base at The Hospital of St Johns and St Elizabeth in London. This development was well received by athletes and coaches and had a positive impact on the speed and quality of diagnostic and early treatment services to athletes, not only in London, but also to athletes travelling from around the UK. The focus was on an early and accurate diagnosis to direct decision-making on further treatment and performance in a risk 


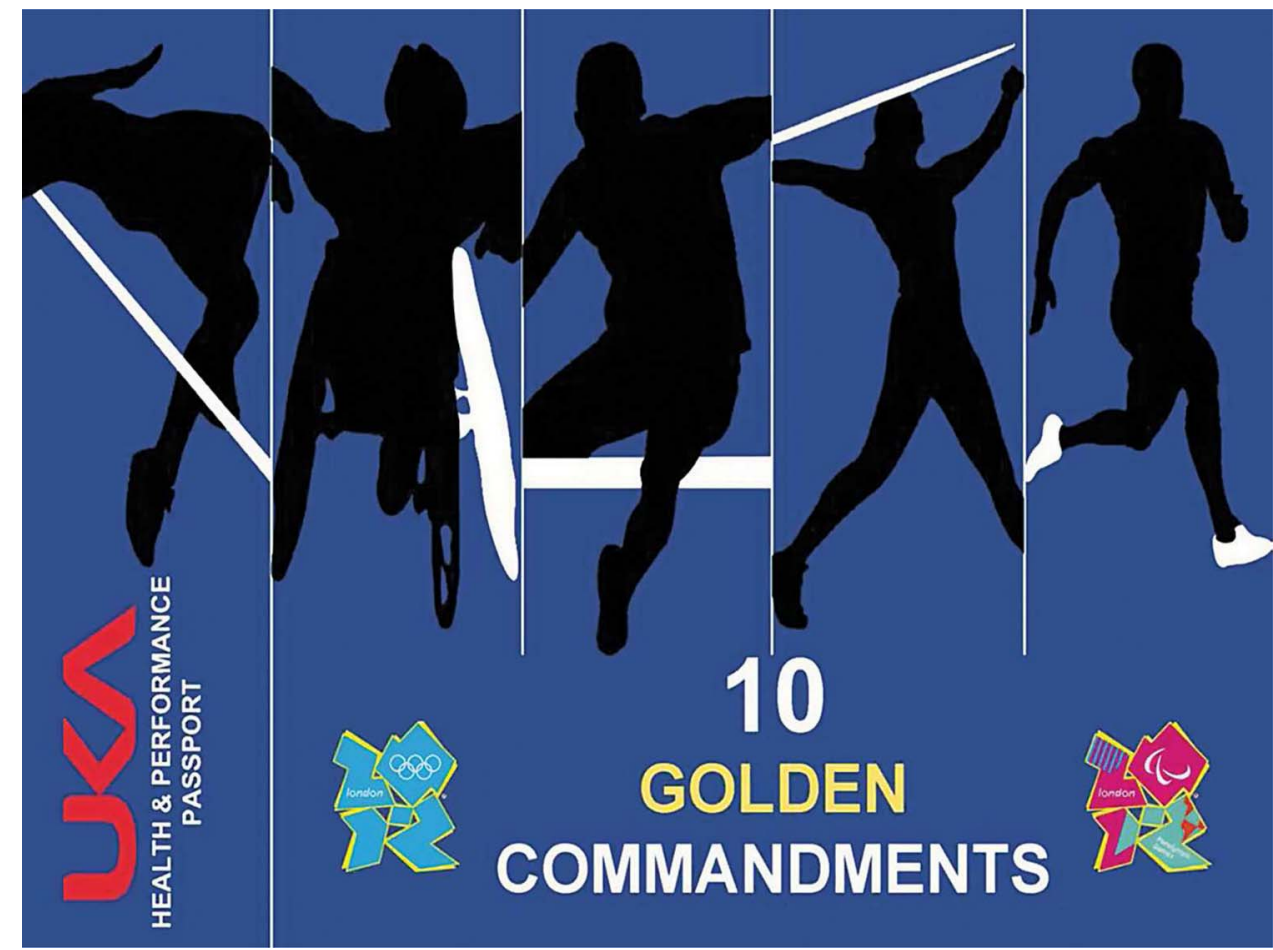

.

Figure 3 The UKA Health and Performance Passport-the 10 Golden Commandments. UKA, UK Athletics.

conscious way. This system also improved the professional governance of clinicians: the medical director of the private hospital base acted as the Responsible Officer for the 5-year cycle of the compulsory General Medical Council (GMC) revalidation process for the London-based UKA sports medicine physicians. ${ }^{15}$

The multibase medical strategy improved integrated problem solving to include anatomical, pathological and functional diagnoses as physicians and physical therapists often performed consultations together and discussed the diagnoses and treatment strategies in the context of ongoing physical loading in training and competition.

The team: relationships, roles and responsibilities

The relationship between a doctor and a coach is important for athlete success, especially when travelling to major competitions. A relationship of mutual trust and respect will improve the quality of performance decision-making and athlete health.

Specialist sports medicine physicians were the clinical case managers for all the athletes-especially important for athletes with acute or chronic health issues. The physicians were assisted by a range of other medical, therapy and science specialists and supported by the trackside and hospital-based infrastructure as discussed above.

The majority of athletes and coaches worked in close partnership with the medical team. Decisions were based on an informed process taking into account the relevant health aspects and the specific individual performance goals.

We feel that the balancing act provided by well trained and experienced sports medicine physicians and physical therapists employed by UKA was an important element to ensure the best possible care, accountability and outcome under the direction of senior management. With specific regard to the responsibilities of the doctor and the physiotherapist, the doctor was responsible for the diagnosis and initial management of illness and musculoskeletal injury. The physiotherapist was responsible for the rehabilitation and exercise prescription required in injury management and to liaise with the coach to ensure appropriate transition in return to training and competition.

\section{Continuous health monitoring and electronic medical record keeping}

In conjunction with a New Zealand-based software company, the UKA medical team developed a bespoke electronic medical record (EMR) keeping and health monitoring system, the UKA Medical and Science Profiler. Doctors and physiotherapists used this online EMR system not only to document important health events, special investigations and treatments but also as a realtime 'readiness to train and compete' colour-coded guideline for funded Olympic and Paralympic athletes. For this, we used a five-colour traffic light system based on the current health status for each active diagnosis to advise the athlete, individual coaches and the Head Coaches on 'fitness to train and compete' issues after regular clinical assessment and reassessment of the athlete (table 3).

This system assisted the medical team to respond appropriately to the inevitable element of risk-taking in elite sporting performance, based on the concept of voluntary and informed decision-making to train and compete. Whether there is a truly voluntary assumption of risk and how elite athletes are possibly influenced to make decisions to compete against their better judgement, are beyond the scope of this article and have been comprehensively discussed in the literature. ${ }^{16}$

The five-colour health monitoring system was simplified to a three-colour system in the weeks before and also during major competitions:

- Green: healthy-low risk

- Orange: some health issues-moderate risk

- Red: significant health issues-high risk

When ill or injured, the athlete and head coach (in conjunction with the personal coach, the lead event coach and the medical team) would then decide on their level of tolerance of 
Figure 4 (A) Poster emphasising the importance of reducing the risk of untimely illness. (B) Poster emphasising the importance of quality sleep. (Photos and design: Anita Mann and Scott Davies.)
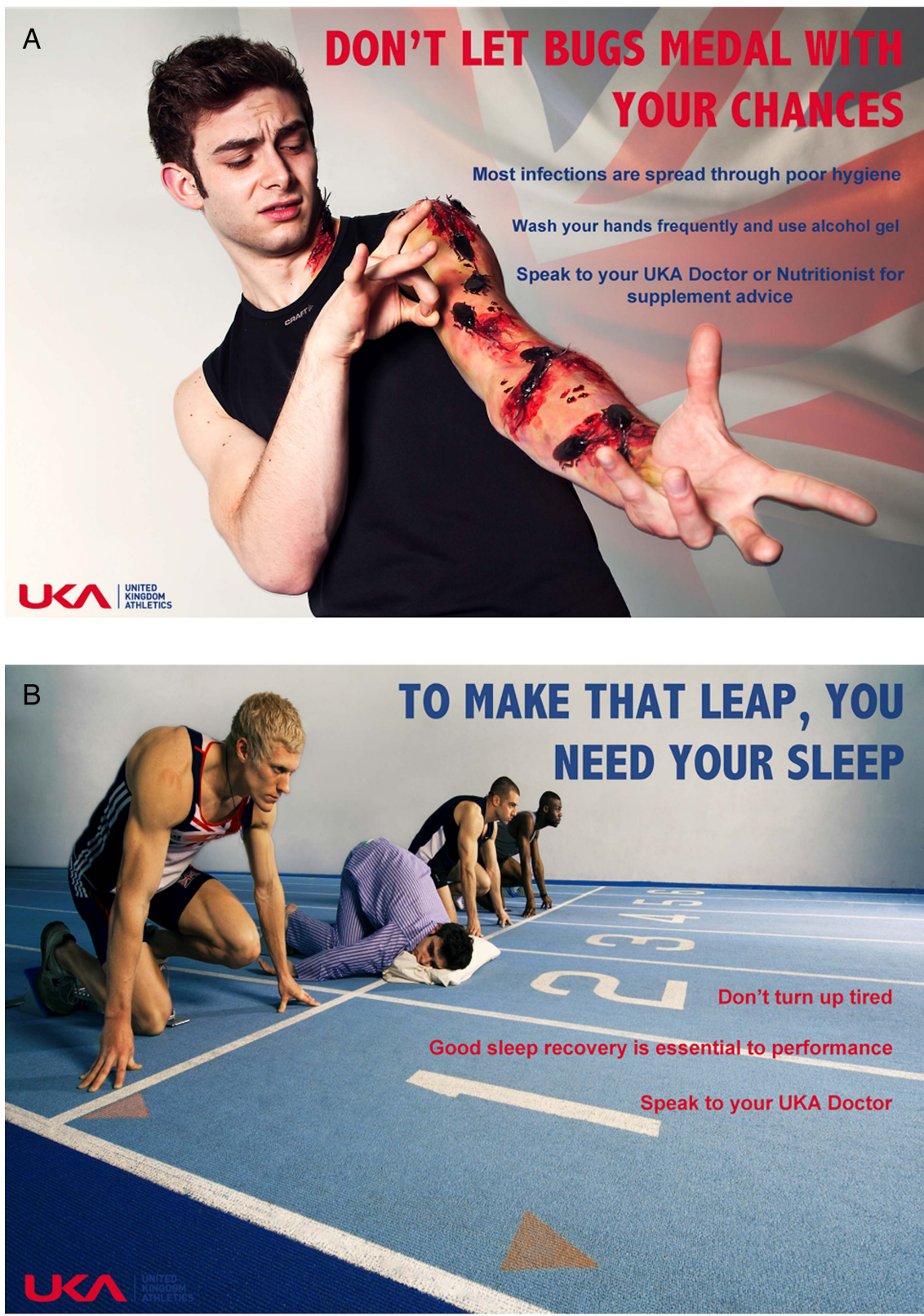

risk and further competition. The decision to compete despite injury or illness was influenced by a number of intrinsic (type of injury) and extrinsic (level of competition) factors.

This approach is very similar to the one recently proposed: The risk/tolerance approach to the preparticipation examination. ${ }^{17}$ After close scrutiny of the individual player's medical history followed by a thorough physical examination, the medical staff assesses the level of risk that a player will be unable to perform or safely compete initially and over the course of the season. The players are sorted into one of four classifications based on the assessment of risk:

- Class 1: Healthy-low risk;

- Class 2: Some health concerns-moderate risk;

- Class 3: Significant concerns-great degree of risk;

- Class 4: Risk too great from a MEDICAL point of view.

It is then the management's ultimate task (owner/president/ team manager/head coach) to decide on the level of tolerance of each player's assessed risk. The UKA medical team did not interfere unnecessarily with performance decisions where the decision to compete when ill or injured was a voluntary one by the athlete and based on good information about the possible health and also performance consequences.

\section{Competition health management: implementing key messages and team selection}

The UKA Medical and Science team prioritised the implementation of important health messages. We have published medical and science guidelines for performance before major competitions since 2007 and continually refined this booklet over time. The Health and Performance Passport (figure 3) was published in preparation for the London 2012 Olympics and Paralympics to assist the medical, science and coaching teams to prioritise the important medical and science aspects of athlete preparation.

This booklet was divided into different sections with space for bespoke notes completed by the athlete, coach and support 


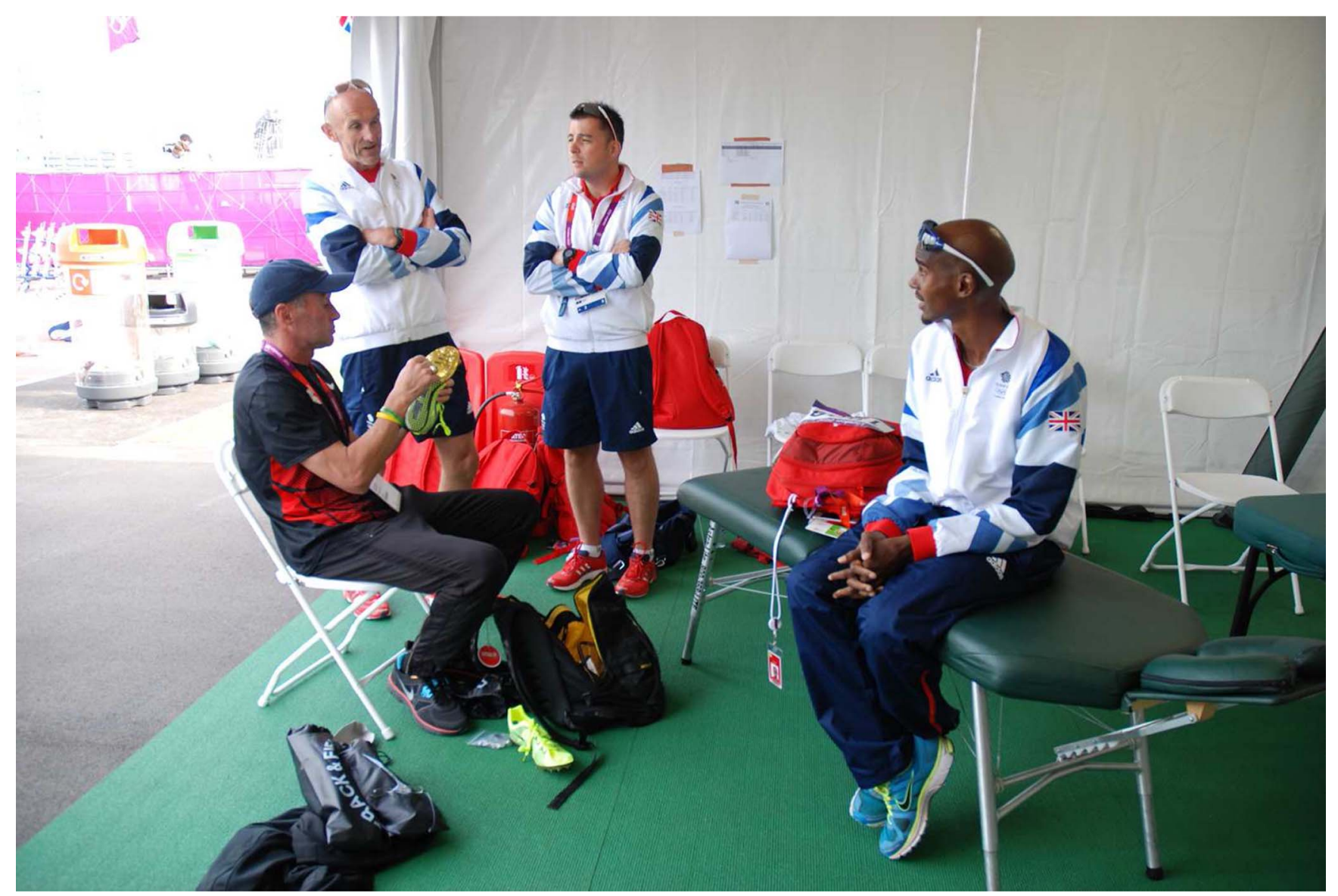

Figure 5 Mo Farah with his coach, physiotherapist and physiologist at the warm-up track, London 2012 Olympic Games.

team. The sections focused on detailed individual planning and organisation including therapy provision, day-to-day planning for the holding camp, the Olympic Village and the important precompetition and competition days. In addition, we provided the athlete and coach with information on health and practical steps to reduce the risk of injury and illness. Finally, we focused on individual nutrition and supplement use, sport psychology and optimising performance and recovery.

In addition to the booklet, we also used key message posters at the training venues and holding camp. Posters focused on topics like the prevention of illness (figure 4A) and the importance of sleep (figure 4B).

The UKA Medical and Science team to the London Olympics had a very diverse training, skills and experience and included two SEM physicians, four physiotherapists, two softtissue therapists, a chiropractor, an osteopath and a sports physiologist. Skills and experience were not the only important aspects-we also prioritised the way we worked together as a professional team (figure 5) and all the team members agreed and signed a code of conduct document at the beginning of our pre-Olympic holding camp.

\section{CONCLUSION}

For many athletes, coaches, clinicians and managers, the integrated and performance-focused approach to elite athlete health and coaching is still a difficult concept. Clinicians are focused on the medical 'evidence' and the physical health of the athlete and often want to have the 'final say' on these matters. They then tend to overlook the potential performance and psychological consequences when making decisions in isolation and when athlete preferences are excluded from the consultation. The reality check of a specific goal or 'preference' is demanded by the athlete-coach team and it might be argued that clinicians choosing to ignore this element only practise 'safe medicine'. They might find it difficult to survive in the elite sport setting. Coaches and athletes are sometimes so performance focused that the health consequences of decisions in the heat of the moment are not taken into account.

\section{What are the new findings?}

- This study proposes a new Integrated Performance Health and Coaching model for the delivery of sports medicine services to elite athletes.

- In this new model, decisions are not taken in isolation and take into account the best medical evidence as well as athlete performance preferences.

- We illustrate the model describing some of the organisational and implementation strategies used by UK Athletics before and during the successful London Olympic Games.

- The experienced sports physician in close collaboration with other members of the multidisciplinary support team is ideally positioned as case manager, especially when the athlete needs to train or compete when ill or injured. 
How might it impact on clinical practice in the near future?

- The guidelines provided on how coaching and support teams should work together in a performance-driven sport environment are useful to sports medicine physicians, coaches and managers.

- Clubs and sport governing bodies may use the framework for the organisational structure and management of medical teams discussed in this paper.

- This study discuss novel implementation strategies used in practice by a successful Olympic and Paralympic Team to improve continuous and performance-driven health management of the athlete.

- One of the implementation strategies, an electronic medical record keeping system, uses a real-time health and performance risk colour coding system, with continuous health management and effective team communication features. This system may be adopted in sports medicine practice and organisations to facilitate integrated decision-making and communication.

It is therefore important to have a critical look at the organisation of medical support services to elite athletes, the process of decision-making in the elite sport environment and the best way to continuously manage athlete health. Athletes cannot do this in isolation and need the support of a well organised and integrated health and coaching team working in harmony towards common goals in a new Integrated Performance Health Management and Coaching model.

Acknowledgements The authors greatly acknowledge the contributions and support, direct or indirect, in writing or in conversation of the UK Athletics Performance teams (2006-2013).

Contributors HPD is responsible for the overall content as guarantor; responsible for the planning, conduct and reporting of the work described in the article including the conception and design of the project, and mainly the proposed new 'The Integrated Performance Health Management and Coaching Model' described in the paper as well as the UK Athletics (UKA) processes and implementation strategies as UKA Chief Medical Officer 2008-2013; primarily responsible for drafting, writing and revision of the manuscript and final approval of the submitted version. NP contributed to the planning, conduct and reporting of the work described in the article, including some contribution to the new 'The Integrated Performance Health Management and Coaching Model' described in the paper and mainly the UKA processes and implementation strategies discussed in the paper as UKA London Medical Officer; contributed to drafting, writing and revision of the manuscript. RC contributed to the planning, conduct and reporting of the work described in the article and mainly the UKA processes and implementation strategies discussed in the paper as UKA Midlands Medical Officer; contributed to the writing and revision of the manuscript. JMA contributed to the planning and writing of the article, including contribution to the new 'The Integrated Performance Health Management and Coaching Model' described in the paper; revising the manuscript critically for important intellectual content.

\section{Competing interests None.}

Provenance and peer review Not commissioned; externally peer reviewed.

Open Access This is an Open Access article distributed in accordance with the Creative Commons Attribution Non Commercial (CC BY-NC 3.0) license, which permits others to distribute, remix, adapt, build upon this work non-commercially, and license their derivative works on different terms, provided the original work is properly cited and the use is non-commercial. See: http://creativecommons.org/ licenses/by-nc/3.0/

\section{REFERENCES}

1 Alonso JM, Junge A, Renström P, et al. Sports injuries surveillance during the 2007 IAAF World Athletics Championships. Clin I Sport Med 2009;19:26-32.

2 Alonso J-M, Tscholl PM, Engebretsen L, et al. Occurrence of injuries and illnesses during the 2009 IAAF World Athletics Championships. Br I Sports Med 2010;44:1100-5.

3 Engebretsen L, Soligard T, Steffen K, et al. Sports injuries and illnesses during the London Summer Olympic Games 2012. Br J Sports Med 2013;47:407-14.

4 Jacobsson J, Timpka T, Kowalski J, et al. Injury patterns in Swedish elite athletics: annual incidence, injury types and risk factors. Br J Sports Med 2013;47:941-52.

5 Shultz R, Bido J, Shrier I, et al. Team clinician variability in return-to-play decisions. Clin J Sport Med 2013;23:456-61.

6 Creighton DW, Shrier I, Shultz R, et al. Return-to-play in sport: a decision-based model. Clin J Sport Med 2010;20:379-85.

7 Williams JGP. Sports medicine. London: The Williams and Wilkins Company, 1962.

8 Pollock N, Dijkstra P, Chakraverty R, et al. Low 25(OH) vitamin D concentrations in international UK track and field athletes. S Afr J Sports Med 2012;24: 55-9.

9 Dijkstra HP, Robson-Ansley P. The prevalence and current opinion of treatment of allergic rhinitis in elite athletes. Curr Opin Allergy Clin Immunol 2011;11: 103-8.

10 Sport and Exercise Medicine. http://www.gmc-uk.org/education/sports and exercise_medicine.asp (accessed 17 Oct 2013).

11 Dijkstra HP, Pollock $N$. The role of the specialist sports medicine physician in elite sport. Managing athlete health while optimising performance- - a track and field perspective. Aspetar Sports Med J 2014;3:24-31.

12 Brukner P, Bahr R, Blair S, et al. Brukner \& Khan's clinical sports medicine. Sydney; New York: McGraw-Hill, 2012.

13 Herring SA, Kibler WB, Putukian M. The team physician and the return-to-play decision: a consensus statement-2012 update. Med Sci Sports Exerc 2012;44:2446-8

14 Quill TE, Holloway RG. Evidence, preferences, recommendations-finding the right balance in patient care. N Eng/ J Med 2012:366:1653-5.

15 Revalidation. http://www.gmc-uk.org/doctors/revalidation.asp (accessed 12 Sep 2013).

16 Anderson L. Doctoring risk: responding to risk-taking in athletes. Sport Ethics Philos 2007:1:119-34.

17 Levy D, Delaney JS. A risk/tolerance approach to the preparticipation examination. Clin J Sport Med 2012;22:309-10. 